\title{
Analisa Unjuk Kerja Flap Sebagai Penambah Koefisien Gaya Angkat
}

\author{
Rifdian I.S \\ Akademi Teknik dan Keselamatan Penerbangan Surabaya \\ Jl.Jemur Andayani 1/73 Wonocolo Surabaya 60236 \\ Telp.(031)841087, Fax.(031)8490005 \\ rifdian.anto@gmail.com
}

\begin{abstract}
The process of takeoff and landing is a crucial factor in the phase offlight, other than because it is on the critical height but also the critical speed. At the time of the landing process required a low speed (no stall), as well as providing a high braking effect is obtained for a smooth landing and sliding distance is relatively short. At that result, in the process of landing a maximumflap deflection is used to produce $C_{\text {Lmax }}$ and drag the highest. At the time the plane accelerate speeds for takeoff, immediately attempted to get the low takeoff speed (no stall), as well as provide a small braking effect to immediately achieved a high rate of speed. Thus required a small flap deflection offlaps on takeoff position.
\end{abstract}

Keyword : flap deflection as lift adder for takeoff and landing process, maximum lift coefficient, stall

\section{Latar Belakang Masalah}

Gaya angkat (lift) yang dihasilkan sayap merupakan fungsi dari kecepatan, luas sayap, bentuk airfoil, serta salah satu properti udara yaitu density (kerapatan). Dari beberapa parameter yang menentukan besar lift tersebut, kecepatan sebagai faktor yang paling dominan. Pada saat pesawat terbang dalam kondisi kecepatan rendah (low speed performance) misalnya saat proses takeoff (tinggal landas) atau landing (mendarat), gaya angkat merupakan kebutuhan yang sangat esensial dalam mengimbangi berat pesawat terbang. Kebutuhan gaya angkat secara cukup sebagai penyeimbang terhadap berat pesawat pada saat takeoff ataupun landing, merupakan masalah mengingat kecepatan pesawat yang masih relatif rendah. Pada sayap pesawat terbang dilengkapi peralatan penambah gaya angkat yang disebut HLD (High Lift Devices), yang digunakan sebagai alat untuk menambah gaya angkat pada saat pesawat terbang sedang dalam kinerja berkecepatan rendah khususnya saat proses pendaratan atau tinggal landas. Salah satu jenis HLD adalah flap, berupa konstruksi bidang yang dipasang pada sayap bagian belakang (trailling edge). Berdasarkan pertimbangan tersebut, pada penelitian ini akan dianalisis tentang kinerja flap sebagai penambah gaya angkat pada saat pesawat dalam kondisi kecepatan rendah.

\section{Landas an Teori}

\section{a. Airfoil/Sayap}

Jika sayap diiris memanjang sejajar dengan bidang yang dibentuk oleh sumbu horizontal dan vertikal pesawat, maka irisan sayap tersebut adalah airfoil. Dengan demikian airfoil juga disebut sayap dua dimensi, karena tidak memperhitungkan panjang sayap (span). Airfoil yang digunakan dalam penelitian ini adalah NACA 0015, yang berarti airfoil berbentuk simetris dengan ketebalan $15 \%$ dari panjang chord. Chord adalah jarak rata-rata antara bagian depan sayap (leading edge) dengan bagian belakang sayap (trailing edge).

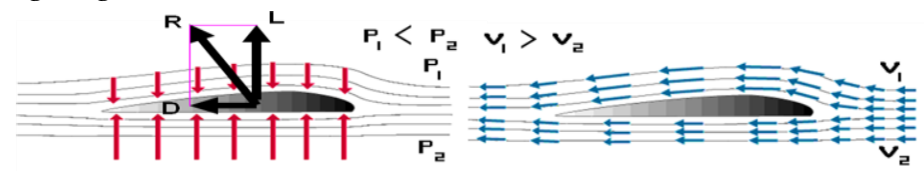

Gambar 1 Distribusi kecepatan dan tekanan, serta lift pada airfoil 
Jika airfoil dikenai aliran udara, maka bentuk camber (lengkung) dari airfoil menghasilkan distribusi kecepatan dan tekanan statik. Kecepatan pada lengkung atas lebih besar dari pada kecepatan pada lengkung bawah, dan sesuai dengan Hukum Bernoulli maka tekanan statik pada lengkung bawah lebih besar dari pada lengkung atas. Perbedaan tekanan statik antara permukaan bawah airfoil yang lebih tinggi dari pada tekanan statik pada permukaan airfoil atas, menghasilkan resultante gaya yang disebut gaya aerodinamik. Gaya aerodinamik (R) dapat diuraikan menjadi dua komponen gaya, yaitu gaya angkat atau lift (L) dan gaya hambat atau drag (D). Lift (L) adalah komponen gaya aerodinamik yang tegak lurus relative wind (vector kecepatan udara relatif terhadap sayap), sedangkan drag (D) adalah komponen gaya aerodinamik yang sejajar dengan relative wind. Lift merupakan fungsi dari kecepatan udara relatif, density udara, luas sayap, dan koefisien gaya angkat $\left(\mathrm{C}_{\mathrm{L}}\right)$. Besar koefisien gaya angkat dipengaruhi oleh bentuk geometri sayap dan sudut serang atau angle of attack $(\alpha)$. Sudut serang adalah sudut yang dibentuk oleh relative wind dan chord. Pada saat besar sudut $\alpha$ rendah sampai sedang, harga $\mathrm{C}_{\mathrm{L}}$ meningkat secara linear terhadap penambahan $\alpha$. Pada saat mendekati sudut serang stall, peningkatan $C_{L}$ menjadi lebih kecil dibanding dengan peningakatan $\alpha$, sehingga kurva $\alpha$ versus $\mathrm{C}_{\mathrm{L}}$ berbentuk parabolis. Akhirnya pada saat sudut serang stall dilampaui $\left(\alpha_{\text {STALL }}\right)$, maka harga $C_{L}$ turun dan penomena inilah yang disebut stall.

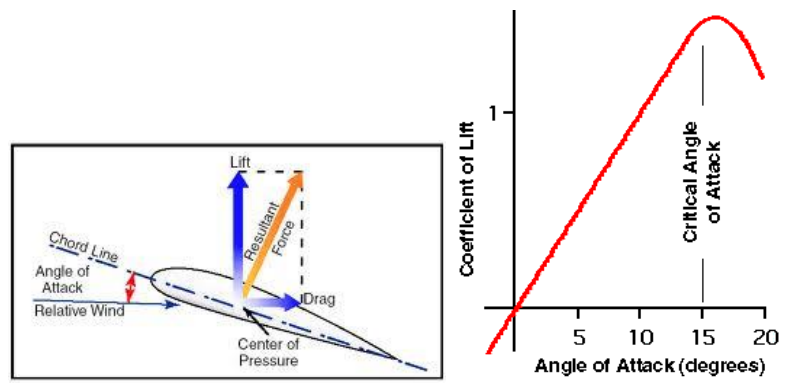

Gambar 2 : Kurva $\mathrm{C}_{\mathrm{L}}$ versus Angle of Attack

Lift yang dihasilkan sayap dinyatakan sebagai berikut :

$$
L=1 / 2 \rho V^{2} S C_{L}
$$

Koefisien gaya angkat $\left(\mathrm{C}_{\mathrm{L}}\right)$, bisa dihitung :

$$
C_{L}=\frac{2 L}{\rho V^{2} S}
$$

Besar $C_{L}$ ditentukan oleh jenis airfoil dan sudut serang $\alpha$. Biasanya penerbang tidak menggunakan besarnya $\alpha$ sebagai referensi terbang, mengingat tidak semua pesawat dilengkapi dengan "AOA indicator" (indicator Angle Of Attack). Sebagai penggantinya digunakan air speed atau kecepatan pesawat terhadap kecepatan udara relatif $(\mathrm{V})$. Jika pesawat pada kondisi straight and level (terbang datar lurus), maka berat pesawat sama dengan lift atau $\mathrm{L}=\mathrm{W}$. Dengan demikian kecepatan dinyatakan sebagai berikut :

$$
V=\sqrt{\frac{2 W}{\rho C_{L} S}} .
$$

Pesawat yang terbang pada $\mathrm{C}_{\mathrm{Lmax}}$ berarti pesawat terbang pada kecepatan stall $\left(\mathrm{V}_{\mathrm{STALL}}\right)$, yang dinyatakan secara matematis :

$$
V_{\text {stall }}=\sqrt{\frac{2 W}{\rho C_{L \max } S}} .
$$

Kecepatan stall adalah kecepatan dimana pesawat terbang pada harga $\mathrm{C}_{\mathrm{Lmax}}$, sehingga kecepatan pesawat masih aman untuk terbang tanpa mengalami stall. Berdasarkan persamaan (4), semakin besar harga $C_{\text {Lmax }}$ menyebabkan harga $V_{\text {STALL }}$ semakin kecil. 
Disamping menghasilkan lift, sayap juga menghasilkan drag yang dinyatakan :

$$
D=1 / 2 \rho V^{2} S C_{D}
$$

Dari persamaan (5), koefisien drag $\left(\mathrm{C}_{\mathrm{D}}\right)$ dapat dihitung :

$$
C_{D}=\frac{2 D}{\rho V^{2} S}
$$

Drag (D) tersebut merupakan gabungan profile drag dan induced drag yang disebut drag total. Profile drag merupakan gabungan dari gaya hambat karena gesekan udara dengan kulit sayap (skin friction drag) dan drag karena bentuk sayap (form drag) atau drag karena distribusi tekanan (pressure drag). Induced drag merupakan drag yang dihasilkan akibat adanya kebocoran tekanan pada ujung sayap.

Flap adalah sebuah bidang yang terpasang pada bagian belakang (trailing edge) atau bagiaan depan (leading edge) sayap. Namun flap yang akan diteliti adalah flap yang terpasang pada trailing edge jenis split flap. Selain split flap, ada beberapa jenis flap yang dipasang pada trailing edge, yaitu plain flap, slotted flap, dan fowler flap seperti pada gambar 3. Flap berfungsi sebagai penambah gaya angkat pada saat pesawat melakukan kinerja pada kecepatan rendah dengan cara meningkatkan harga $\mathrm{C}_{\mathrm{Lmax}}$. Semakin besar harga $C_{\text {Lmax }}$ akan semakin memperkecil $V_{\text {STALL, }}$ seperti persamaan 4 .

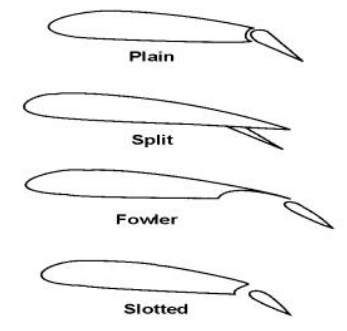

Gambar 3 : Jenis flap

Dengan demikian pesawat akan tetap aman atau tidak terjadi stall, meskipun melaju dalam kecepatan rendah. Flap jenis split dalam meningkatkan $\mathrm{C}_{\mathrm{Lmax}}$, dilakukan dengan cara merubah geometri sayap. Pada saat posisi flap netral, berarti geometri sayap adalah bentuk sayap dari airfoil yang digunakan dalam penelitian yaitu NACA 0015. Namun pada saat flap disimpangkan (defleksi ke bawah), maka terjadi perubahan geometri sayap sehingga $\mathrm{C}_{\mathrm{Lmax}}$ akan meningkat meskipun dengan sudut serang yang sama dengan saat flap netral. Demikian seterusnya, sehingga setiap peningkatan derajat defleksi flap akan diperoleh harga $C_{L \max }$ yang lebih besar.

\section{Metodologi Penelitian}

a. Alat Yang Digunakan.

Alat yang digunakan untuk penelitian adalah terowongan angin kecepatan rendah (Low Speed Wind Tunnel) dengan kecepatan udara maksimum $20 \mathrm{~m} / \mathrm{dtk}$. Terowongan angin terbuat dari resin, dengan permukaan dinding dalam terowongan yang dibuat sehalus dan serata mungkin guna memperkecil ketebalan lapis batas aliran (boundary layer). Terowongan angin dibagi dalam tiga bagian, yaitu bellmouth section, working section (seksi kerja), dan bagian diffuser. Guna mendapatkan kecepatan udara, digunakan kipas penyedot udara (blower) yang bisa dikendalikan kecepatannya melalui converter. Alat ukur yang digunakan adalah pengukur kecepatan dengan menggunakan tabung pitot, pengukur lift dan drag dengan timbangan, pengukur sudut serang, sedangkan untuk mengukur kondisi udara diperlengkapi thermometer, barometer dan hydrometer. Pengukur kecepatan berupa manometer posisi miring (tilting manometer) yang dikalibrasi dalam bentuk ukuran kecepatan (meter/detik).

Data-data teknik secara detail adalah sebagai berikut :

1. Masukan Power Listrik

2. Power Motor

3. Panjang

4. Tinggi

5. Lebar

6. Kecepatan maksimum
$240 \mathrm{~V} / 50 \mathrm{Cps}$

$1.5 \mathrm{Kw}$

2.98 meter

1.83 meter

0.8 meter

20 meter/detik 
7. Gaya Angkat Maksimum

7 Newton

8. Gaya Hambat Maksimum

2.5 Newton

9. Ketelitian Ukuran

\subsection{Newton}

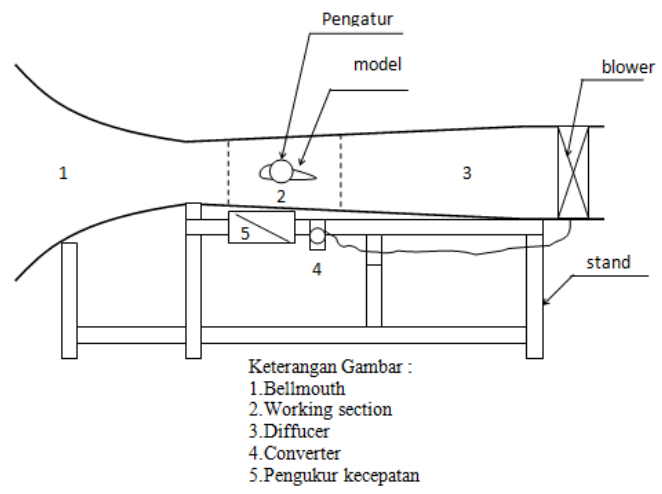

b. Bahan Uji

Gambar 4 : Terowongan Angin subsonik rendah

Sebagai bahan uji digunakan model sayap airfoil NACA 0015 yang dilengkapi trailing edge flap jenis split flap. Model sayap yang digunakan dengan chord berukuran $0,1015 \mathrm{~m}$ dan span $0.1251 \mathrm{~m}$, sehingga luas sayap $0.12511 \mathrm{~m}^{2}$. Flap jenis split yang dipasang di bagian trailing edge dapat diatur pada posisi $0^{\circ}$ (netral), pada sudut $15^{\circ}, 30^{\circ}, 45^{\circ}$, dan $60^{\circ}$. Model sayap dilengkapi dengan tangkai yang bisa dipasangkan pada alat penimbang secara tepat, sehingga gaya angkat dan gaya hambat pada model bisa diukur.

\section{c. Cara Pengujian}

Bahan uji dipasang pada ruang uji dengan cara mengikat tangkai sayap dengan sekrup yang sekaligus menghubungkan bahan uji dengan pengukur lift dan drag. Sebelum pengujian, dilakukan pencatan suhu dan tekanan ruangan, yang selanjutnya dianggap sebagai suhu dan tekanan stagnasi.

Bahan uji diuji pada kecepatan $12.5 \mathrm{~m} / \mathrm{dtk}$ yang dinyatakan dalam angka Reynolds (Re), yaitu :

$$
R_{e}=\frac{\rho V c}{\mu}
$$

Karena $\frac{\mu}{\rho}=v$, maka persamaan (8) menjadi :

$$
R_{e}=\frac{V c}{v}
$$

Dengan memasukkan harga kecepatan $(\mathrm{V})=12.5 \mathrm{~m} / \mathrm{dtk}, \mathrm{c}$ (chord) $=0.1015 \mathrm{~m}$, dan $\mathrm{v}$ (viskositas kinematik) pada suhu $27^{\circ} \mathrm{C}$ atau $300 \mathrm{~K}=15.8910-6 \mathrm{~m}^{2} / \mathrm{dtk}$ ), maka pengujian dilakukan pada $\mathrm{Re}=$ 79846.

Tabel Data Pengujian dan Hasil Perhitungan

Taupa flap
\begin{tabular}{|c|c|c|c|c|}
\hline A & Lift & Drag & C $_{2}$ & C $_{3}$ \\
\hline-3 & -0.32 & 0.04 & -0.2961 & 0.0370 \\
\hline 0 & 0 & 0.04 & 0.0000 & 0.0370 \\
\hline 3 & 0.32 & 0.06 & 0.2961 & 0.0555 \\
\hline 6 & 0.6 & 0.07 & 0.5552 & 0.0666 \\
\hline 9 & 0.96 & 0.10 & 0.8883 & 0.0888 \\
\hline 12 & 1.24 & 0.12 & 1.1474 & 0.1110 \\
\hline 13 & 1.28 & 0.14 & 1.1844 & 0.1295 \\
\hline 14 & 1.2 & 0.16 & 1.1104 & 0.1481 \\
\hline
\end{tabular}

Flap 15
\begin{tabular}{|c|c|c|c|c|}
\hline A & Lift & Drag & C $_{1}$ & C $_{z}$ \\
\hline-3 & 0.5 & 0.15 & 0.4627 & 0.1388 \\
\hline 0 & 1.55 & 0.16 & 1.4342 & 0.1481 \\
\hline 3 & 2.39 & 0.2 & 2.2115 & 0.1851 \\
\hline 6 & 3.1 & 0.3 & 2.8685 & 0.2776 \\
\hline 9 & 3.92 & 0.34 & 3.6272 & 0.3146 \\
\hline 11 & 4.19 & 0.41 & 3.8771 & 0.3794 \\
\hline 12 & 3.54 & 0.65 & 3.2756 & 0.6015 \\
\hline
\end{tabular}
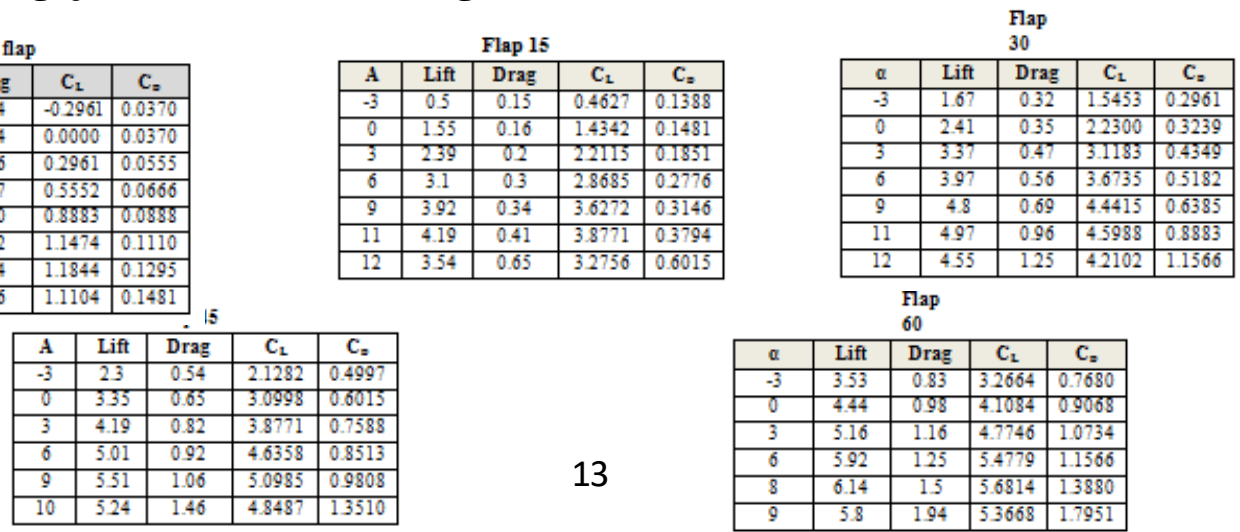

13

\begin{tabular}{|c|c|c|c|c|}
\multicolumn{9}{|c|}{60} \\
\hline$\alpha$ & Lift & Drag & $\mathrm{C}_{1}$ & $\mathrm{C}_{z}$ \\
\hline-3 & 3.53 & 0.83 & 3.2664 & 0.7680 \\
\hline 0 & 4.44 & 0.98 & 4.1084 & 0.9068 \\
\hline 3 & 5.16 & 1.16 & 4.7746 & 1.0734 \\
\hline 6 & 5.92 & 1.25 & 5.4779 & 1.1566 \\
\hline 8 & 6.14 & 1.5 & 5.6814 & 1.3880 \\
\hline 9 & 5.8 & 1.94 & 5.3668 & 1.7951 \\
\hline
\end{tabular}


Urutan pengujian dimulai :

1. Sayap diatur dengan flap $0^{0}$, selanjutnya motor blower dihidupkan dan diatur kecepatannya pada $12.5 \mathrm{~m} / \mathrm{dtk}$.

2. Geser pengatur sudut $\alpha$ mulai $-3^{0}, 0^{0}, 3^{0}, 6^{0}, 9^{0}$, dan seterusnya. Pada saat mendekati sudut stall, pergeseran diatur dengan interval kecil (setiap satu derajat). Setiap posisi sudut pada saat telah stabil, dilakukan pencatatan lift dan drag.

3. Mengulang pengujian seperti tersebut dalam nomor urut 2) dengan mengatur flap pada posisi $15^{\circ}, 30^{\circ}, 45^{\circ}$, dan $60^{\circ}$.

\section{Hasil Penelitian}

Dari pengujian diperoleh data berupa besarnya $C_{L}$ dan $C_{D}$ mulai dari $\alpha=-3$ sampai $\alpha_{\text {stall }}$ dengan interval $3^{0}$, kecuali pada $\alpha$ mendekati stall dengan interval $1^{0}$ dengan tujuan agar memperoleh sudut stall secara lebih tepat. Selanjutnya dengan menggunakan persamaan 2 dan 6 , diperoleh harga koefisien gaya angkat $\left(C_{L}\right)$ dan koefisien gaya hambat $\left(C_{D}\right)$. Kerapatan udara $(\rho)$ dihitung dengan membandingkan tekanan, suhu, dan density antara kondisi dimana pengujian dilaksanakan terhadap tekanan, suhu, dan kerapatan udara sesuai standar atmosfer permukaan air laut. Dalam hal ini, udara diasumsikan sebagai gas ideal dengan konstanta gas yang tidak berubah pada suhu dimana pengujian dilakukan dengan suhu permukaan air laut. Persamaan tersebut adalah:

$$
\begin{aligned}
& \frac{p}{T \rho}=\frac{p_{0}}{T_{0} \rho_{0}} . \\
& \rho=\rho_{0} \frac{T_{0}}{p_{0}} \frac{p}{T}
\end{aligned}
$$

Kerapatan udara $(\rho)$ pada persamaan 10 dapat dihitung dengan memasukkan harga $\rho_{0}=1.225$ $\mathrm{kg} / \mathrm{m} 3, \mathrm{~T}_{0}=288 \mathrm{~K}, \mathrm{p}_{0}=760 \mathrm{mmHg}, \mathrm{p}=756 \mathrm{mmHg}, \mathrm{T}=300 \mathrm{~K}$.

Maka diperoleh harga kerapatan udara $(\rho)=1.1699 \mathrm{~kg} / \mathrm{m}^{3}$.

Data penelitian dan hasil perhitungan disusun dalam tabel, dan selanjutnya dibuat grafik $\mathrm{C}_{\mathrm{L}}$ versus $\alpha$ (gambar 5) dan $C_{D}$ versus $\alpha$ seperti (gambar 6). Berdasarkan hasil perhitungan diperoleh :

a. Defleksi flap menghasilkan peningkatan $C_{L \max }$. Harga $C_{L \max }$ sayap tanpa flap (flapless) dengan sayap dengan flap defleksi $15^{\circ}, 30^{\circ}, 45^{\circ}$, dan $60^{\circ}$, masing-masing sebesar 1.1844 , 3.8771, 4.5988, 5.0985, dan 5.6814. Dengan demikian peningkatan beda koefisien gaya angkat $\left(\Delta \mathrm{C}_{\mathrm{Lmax}}\right)$ antara sayap flapless dengan flap defleksi $15^{\circ}$, diperoleh $\left(\Delta \mathrm{C}_{\mathrm{Lmax}}\right)$ sebesar 2.69, antara flapless dengan flap defleksi $30^{\circ}$ sebesar 3.41, antara flapless dengan defleksi flap $45^{\circ}$ sebesar 3.91, dan antara flapless dengan defleksi flap $60^{\circ}$ sebesar 4.5.

b. Sudut stall ( $\alpha_{\text {stall }}$ ) pada setiap peningkatan defleksi flap semakin turun, yang berarti kemiringan kurva (slope) semakin bergeser ke kiri, sehingga untuk sayap dengan defleksi flap pada sudut $\alpha$ negatif tetap menghasilkan lift. Dengan kata lain bahwa sudut serang yang tidak menghasilkan lift (zerolift angle of attack) bergeser ke kiri ( $\alpha$ negatif).

c. Koefisien gaya hambat $\left(\mathrm{C}_{\mathrm{D}}\right)$ akan semakin meningkat pada setiap penambahan defleksi flap.

\section{Pembahasan}

Pada setiap penambahaan defleksi flap akan menghasilkan peningkatan $\mathrm{C}_{\mathrm{Lmax}}$ dan peningkatan koefisien gaya hambat $\left(\mathrm{C}_{\mathrm{D}}\right)$. Kondisi ini dimanfaatkan untuk keperluan kinerja pesawat pada saat kecepatan rendah, khususnya pada saat proses tinggal landas dan mendarat.

\section{a. Proses Mendarat.}

Dalam proses pendaratan ada beberapa fator yang diperlukan, yaitu : 
1) Kecepatan Approach Yang Rendah. Pesawat yang sedang dalam proses pendaratan terutama di daerah final approach, membutuhkan kecepatan approach $\left(\mathrm{V}_{\mathrm{app}}\right)$ yang rendah, agar pesawat hanya membutuhkan landasan luncur yang relatif pendek. Pada dasarnya kecepatan approach adalah :

$$
\mathrm{V}_{\text {app }}=1.2 \mathrm{~V}_{\text {stall }}
$$

Agar $\mathrm{V}_{\text {app }}$ rendah, maka $\mathrm{V}_{\text {stall }}$ dibuat serendah mungkin dengan cara meningkatkan $\mathrm{Cl}_{\max }$ secara maksimal (persamaan 4). Dengan demikian guna mendapatkan $\mathrm{V}_{\text {app }}$ serendah mungkin, maka diperlukan defleksi flap yang maksimal $\left(60^{\circ}\right)$.

2) Efek Pengereman Yang Tinggi. Selain $V_{\text {app }}$ yang rendah, pada saat proses pendaratan dibutuhkan efek pengereman yang tinggi agar membantu pesawat dapat meluncur dengan menggunakan landasan yang relatif pendek. Dengan demikian dibutuhkan gaya hambat yang besar, yang diperoleh melalui defleksi flap yang maksimal $\left(60^{\circ}\right)$.

3) Visibilitas Penerbang. Pada proses pendaratan, posisi pesawat harus memberikan jaminan visibilitas yang baik bagi penerbang. Saat pesawat pada posisi descend atau gliding (posisi pesawat terbang menurun) untuk melakukan landing approach, sumbu longitudinal pesawat membentuk sudut negatif terhadap horison. Posisi ini akan mengurangi sudut serang, sehingga pesawat terbang dengan sudut serang relatif kecil. Pesawat yang terbang dengan sudut serang kecil dan kecepatan yang rendah karena melakukan proses pendaratan, hanya menghasilkan gaya angkat yang rendah. Kondisi ini diatasi dengan defleksi flap maksimal $\left(60^{\circ}\right)$, sehingga diperoleh gaya angkat $\left(\mathrm{C}_{\mathrm{L}}\right.$ positif) meskipun pesawat terbang pada sudut serang kecil atau bahkan sudut serang negatif. Dengan demikian pesawat terbang dengan posisi descend atau gliding memberikan jaminan visibilitas penerbang yang baik, dan pesawat tetap menghasilkan gaya angkat yang cukup untuk mengimbangi berat pesawat.

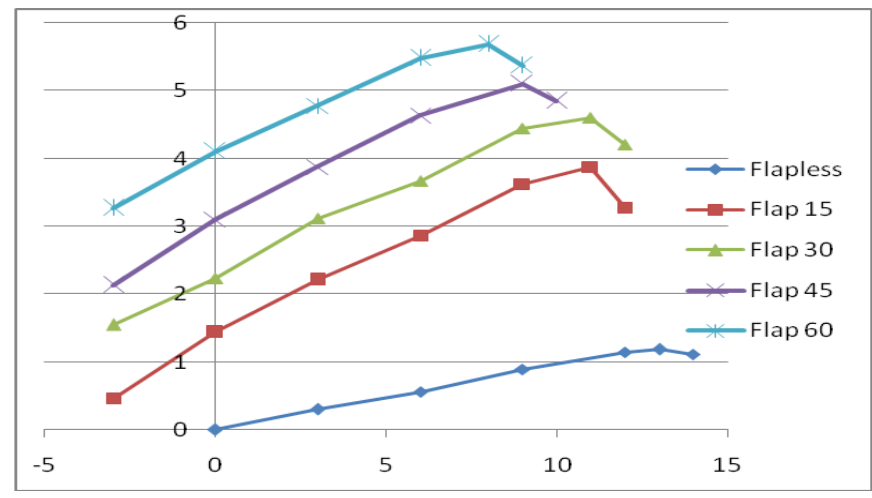

Gambar 5 : Grafi $C_{L}$ versus $\alpha$

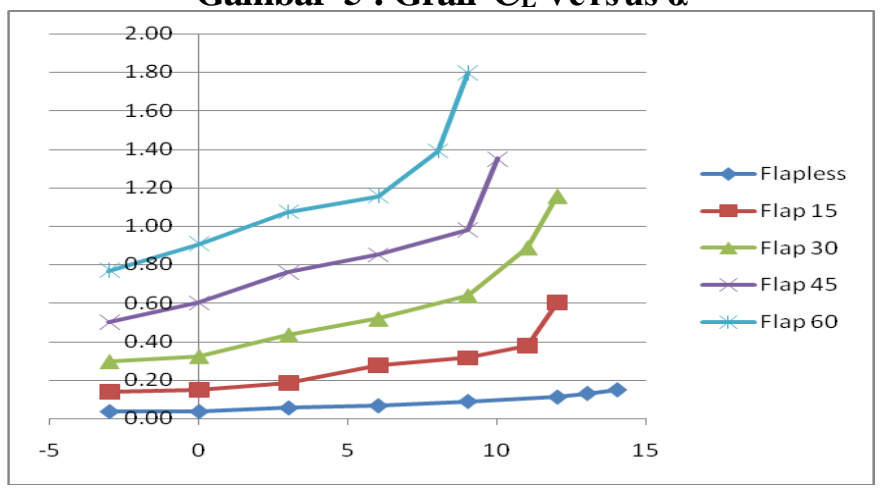

Gambar 6 : Grafik CD versus $\alpha$ 


\section{b. Tinggal Landas}

Proses tinggal landas dimulai dari run up di ujung landasan, kemudian pesawat mulai bergerak dengan memacu kecepatan. Setelah diperoleh kecepatan cukup, maka pesawat mulai tinggal landas (airborn). Kecepatan tinggal landas adalah kecepatan minimal pesawat untuk bisa airborn, yang tentu saja harus lebih tinggi dari $\mathrm{Vs}_{\text {tall }}$. Dengan demikian semakin rendah $\mathrm{V}_{\text {stall, }}$, maka kecepatan tinggal landas segera tercapai, sehingga pesawat bisa tinggal landas dengan menggunakan landasan yang lebih pendek. Penurunan $\mathrm{V}_{\text {stall }}$ dilakukan dengan cara defleksi flap, namun penggunaan flap harus disertai dengan peningkatan gaya hambat yang kecil. Dengan demikian penggunaan flap pada saat tinggal landas, menggunakan defleksi flap yang kecil antara $15^{\circ}$ sampai dengan $30^{\circ}$, yang biasanya sudah diatur pada flap posisi take off.

\section{Kesimpulan}

Berdasarkan hasil pengujian sayap airfoil NACA 0015 yang dilengkapi flap jenis split, menunjukkan bahwa :

a. Setiap penambahan defleksi flap akan menghasilkan peningkatan $C_{L m a x}$ dan penurunan $\alpha_{\text {stall }}$, sehingga slope kurca $\mathrm{C}_{\mathrm{L}}$ versus $\alpha$ semakin bergeser ke kiri. Dengan semakin bergesernya kurva $\mathrm{C}_{\mathrm{L}}$ versus $\alpha$ ke kiri, maka pada sudut $\alpha$ kecil bahkan negatif tetap menghasilkan gaya angkat $\left(\mathrm{C}_{\mathrm{L}}\right.$ positif). Setiap penambahan defleksi flap juga menghasilkan penambahan gaya hambat yang terlihat pada peningkatan $\mathrm{C}_{\mathrm{D}}$.

b. Berdasarkan penomena tersebut, maka flap digunakan sebagai penambah gaya angkat pada saat kecepatan rendah, yang antara lain dimanfaatkan pada saat proses mendarat dan tinggal landas. Pada saat proses mendarat dibutuhkan kecepatan approach yang rendah tetapi tetap aman, serta efek pengereman yang tinggi. Olek karena itu pada proses pendaratan digunakan sayap dengan defleksi flap maksimal $\left(60^{\circ}\right)$. Kemudian pada saat proses tinggal landas, agar secepatnya memperoleh kecepatan tinggal landas yang aman, maka perlu peningkatan $C_{L}$ dengan defleksi flap. Namun agar peningkatan $\mathrm{C}_{\mathrm{L}}$ tidak diikuti peningkatan gaya hambat yang tinggi akibat defleksi flap, maka untuk kepentingan tinggal landas digunakan defleksi flap yang kecil.

\section{DAFTAR PUSTAKA}

E.L. Houghton dan AE. Brock, 1977, Aerodynamics For Engineering Students, Edward Arnold, London. Barnes W. Mc Cormich, 1977, Aerodynamics Aeronautics And Flight Mechanics, Jonh Wiley and Sons Inc.

Darrol Stinton, 1966, The Anatomy Of Aeroplane, GT Foulis \& Co Great Britain.

LJ. Clancy, 1975, Aerodynamics, Great Britain.

Charles E. Dole, 1981, Flight Theory And Aerodynamics, Jonh Wiley \& Sons Inc.

Jonh D. Anderson Jr., 1984, Fundamentals Of Aerodynamics, Mc Graw Hill Inc.

Abboth H. Ira and Von Doenhof, 1959, Theory of Wing Section, Dover Publication, NY. 